\author{
EVS29 Symposium \\ Montréal, Québec, Canada, June 19-22, 2016
}

\title{
Implications of Successes and Failures of BEV-Focused Incentive Support for PEVs in the U.S., Canada and Europe
}

\author{
D. Santini ${ }^{1}$, M. Rood ${ }^{1}$, Y. Zhou ${ }^{1}$, T. Stephens ${ }^{1}$, J. Miller ${ }^{1}$, L. Bluestein ${ }^{3}$ \\ ${ }^{\text {I} A r g o n n e ~ N a t i o n a l ~ L a b o r a t o r y, ~} 9700$ S Cass Ave, Lemont, IL, USA, dsantini@anl.gov \\ 3U.S. Department of Energy, 1000 Independence Ave. SW, Washington DC, USA
}

\begin{abstract}
Short Abstract
An international comparative analysis of causes of variation of PEV sales rates per capita in selected U.S. states, Canadian provinces, and European Nations is conducted. 2014-15 light-duty PEV registrations/sales by make and model are examined, drawing heavily on 2014 data for aggregate comparisons. States, provinces, and nations with PEV success, but with widely varying PEV purchase incentives and charging infrastructure installations are examined. The paper focuses particularly presence or absence of long daily distance charging options for PEVs. Four questions are addressed. (1) European evidence is that PHEV powertrains are a very marketable option for large family vehicles. For small BEVs BMW i3 sales patterns indicate that range extension beyond $120 \mathrm{~km}$ but less than $240 \mathrm{~km}$ via gasoline significantly increases market share. BEV inter-city functionality provided by aggressive installation of DC fast charging was critical to overall PEV success in Norway. Norway, like Northern Europe and Canada has a utility network that is winter peaking, which allows provision of peak summer BEV long-distance charging needs without difficulty. This is not the case for the U.S., which is summer peaking. The reviewed states, provinces, and nations vary considerably in seasonal peak temperature extremes. These climate differences have a significant bearing on the local viability of PHEVs vs. BEVs. The long distance DC fast charging infrastructure investments needed to support BEV market success are not as large when PHEVs are preferred by consumers.
\end{abstract}

Key words: PEV, PHEV, BEV, electric range

\section{Introduction}

\subsection{Broad questions about which technology innovation paths to promote}

This paper presents results of an international comparative analysis of 2012-15 light-duty PEV registrations/sales by make and model, drawing heavily on 2014 data for comparisons across U.S. states, Canadian provinces, and European nations. Selected states and nations with widely varying PEV purchase incentives and charging infrastructure installations are examined to assess the influence of these choices. The paper focuses particularly presence or absence of long daily distance charging options for PEVs. Four questions are examined. (1) What to date has been the best technological package to provide vacation and recreation travel capability for PEVs? (2) How important was range extension (beyond $120 \mathrm{~km}$ ) to the overall marketability of such PEVs? (3) Is a standard method of range extension for intercity travel likely to emerge from the multiple competing technological options? (4) What infrastructure incentives to support PEV sales are the best options for possible U.S. state supplements of the reviewed policies?

The paper has a U.S. centric bias. The examination of both Europe and Canada is intended to broaden the perspective of a policy discussion that is primarily U.S. oriented. With regard to regulation of the light duty motor vehicle in the U.S., there are two fundamentally different paths that states may adopt. Regulations developed by the California Air Resources Board (CARB) may be followed, or federal regulations set by the U.S. Environmental Protection Agency (EPA). CARB and EPA both have "criteria 
pollutant" and Greenhouse Gas (GHG) regulatory authority. Criteria pollutant authority has existed for several decades. GHG regulation is relatively new.

Adoption of CARB regulations means that the state will have "zero emissions vehicle" (ZEV) regulations. These regulations are complex. For our purposes, the policy issue is whether or not CARB ZEV regulations impede the U.S. introduction of plug-in electric drive vehicles that could sell in large numbers. The historical intent of the CARB regulations has been long-term technology development of vehicles that will always have zero tailpipe emissions. Elimination of gasoline combustion within metro areas with significant air quality problems has been a long term goal. For the near-term, as a part of the technology development strategy, plug-in vehicles that can run both on electricity and gasoline are awarded credits. The CARB regulations evolve slowly and involve a lot of interaction with industry concerning specific proposals for vehicle configurations that can contribute to CARB long-term goals.

A current debate is whether or not more kilometers of travel will be electrified via sales of Battery Electric Vehicles (BEVs) or Plug-in Hybrid Electric Vehicles (PHEVs) of various types [1]. This debate assumes an either/or trade-off. Authors of [2] raise the more interesting question. Rather than finding the best single plug-in vehicle for a household, search for the best combination of two vehicles in multi-vehicle households. Authors of [2] conclude that a "PHEV and modest-range EV in multi-vehicle households will always be more cost-effective means to electrify personal travel than are general-purpose EVs." Although [2] estimates that many multi-vehicle households should find this combination acceptable, acceptable is not the same as desirable. It may be important for short-range battery electric vehicles (BEVs) to have a gasoline range extension feature as an option for occasional long-distance travel to be widely acceptable, even in multi-vehicle households. The other option is to seek full function long-distance capability for a small and large pair of "general purpose" BEVs, with significant new electric charging infrastructure placed between cities. This paper addresses these questions by focusing on sales patterns for available vehicles across states, provinces, and nations that have adopted very different strategies with respect to the best first step in PEV technology promotion. If the long distance travel capabilities of PHEVs are so superior to BEVs that the sales volume of PHEVs, and total gasoline saved could be much higher, then it would be desirable to adapt regulations to encourage (or cease to discourage) the technology packages that will sell in much larger volume. This paper goes beyond the discussion of best PEV design to consider grid impacts of the alternative choices should widespread success be obtained.

The U.S., Europe, Canada, and other nations are promoting plug-in vehicle technology development with combinations of regulation and financial incentives. Present fuel economy and greenhouse gas regulations in North America and Europe vary significantly from one another. Driving patterns are also very different, with Europeans traveling considerably less annual miles than North American drivers. Resulting differences in manufacturer vehicle offerings and consumer responses are testing assumptions about which technology innovation path to promote.

\subsection{A summary of U.S. findings}

In companion papers $[3,4]$ we have addressed 2014 U.S. consumer behavior patterns without looking at lessons from Canada and Europe. When we divided the plug-in vehicles available into three market segments based on price (Tables 1-3), it was observed that the PHEV obtained largest shares of total available plug-in vehicles (PEVs) in the low price segment, while the BEV captured the largest share in the high price luxury/performance segment. In the low price segment (Table 1), the rated range of the BEVs varied from 100 to $135 \mathrm{~km}$. In the luxury performance market (Table 3), the rated range of available Tesla Model S powertrains was from 335-434 km. Thus, as driving range of BEVs increased, they captured a larger share of the PEV market, but this was only accomplished for large vehicles within the luxury/performance segment.

Another factor addressed in these two papers was the effect of climate on mix of BEVs vs. PHEVs. Since the actual real world range of the BEV declines significantly at extreme temperatures, particularly in the cold, BEV shares were reduced as buyers shifted to PHEVs to assure extreme temperature range. U.S. states were divided into three climate groups - cold, warm, and moderate. Only the three Pacific Coast states (California, Oregon, and Washington) had moderate temperatures according to our definition (see Fig. 1). Although these three states did have some of the highest amounts of PEVs among registered vehicles, the hypothesis that BEV share would be best in those locations did not hold for the shorter range BEVs - those in Tables 1 and 2. However, when the range of the BEVs were $335 \mathrm{~km}$ and above, making the BEV more suitable for intercity trips, the hypothesis was supported and the average share of BEVs was highest in the moderate temperature states. Generally, our analysis of 2014 registrations data was 
consistent with the findings of [5] that cold temperatures reduced BEV share of U.S. PEV registrations in 2013.

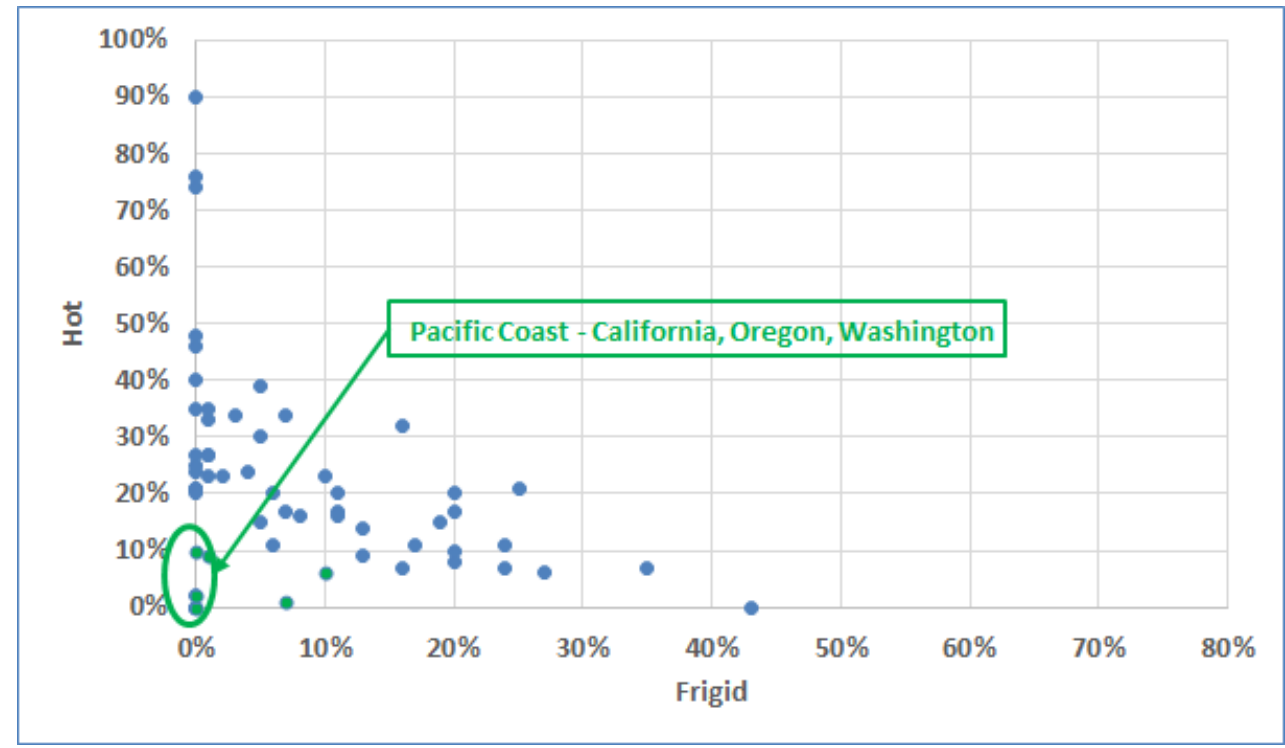

Fig. 1 Peak extreme temperature shares of U.S. cities (Weatherspark.com, averages).

Norway is of particular interest because it clearly is an outlier with respect to accomplishing a large share of BEVs in a relatively cold climate. Oslo, Norway is colder than most, but not all major U.S. cities. However, exhibiting a coastal weather effect, Bergen and Stavanger qualify as moderate, while Trondheim would be in our warm category. Generally, compared to the U.S., Northern Europe has a much milder climate, which should make it a more favorable location for BEVs (Table 2). In the plot below Mediterranean nations are not included. The dots with more than $10 \%$ frigid temperatures on winter peak days are for cities in Norway and Estonia. Otherwise, major northern European large cities have moderate climate.

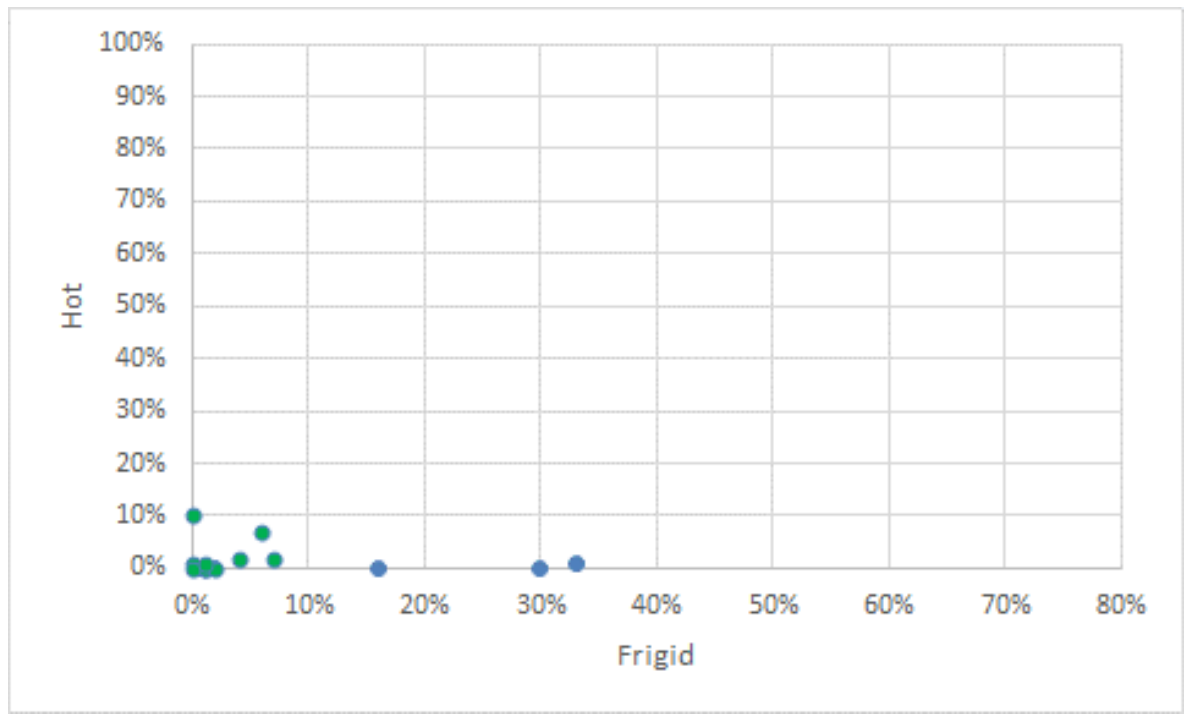

Fig. 2 Peak extreme temperature shares of Northern European cities (Weatherspark.com, averages).

\subsection{Grid capacity vs. charging load from long distance travel}

The absence of very hot summers in Northern Europe has an influence on the electrical loads of the grid. Where the United States grid loads are summer peaking, those in Northern Europe are winter peaking [5, 6]. This is relevant for the cost impacts of the likely electrical loads that would be imposed by BEVs traveling extra miles due to long distance driving in the summer (or winter) peak. The authors of [8] divide U.S. long-distance pleasure travel into two categories - visiting friends and relatives (VFR) and other leisure. They find that the average distance of such trips is about the same, $962 \mathrm{~km}$ for VFR and 816 for other. The timing of the VFR trips involves a fourth quarter (Oct.-Dec.) peak share of $30 \%$, while other 
leisure travel is summer peaking, with $39 \%$ occurring in the July-Sept. quarter. The overall long distance profile is summer peaking. For Northern Europe this would not be a problem, since there would be extra capacity in the summer. However, in the event of mass-market success of general purpose BEVs in the U.S., long distance summer travel by those BEVs would cause a need for more summer generation capacity. It should be noted, however, that the seasonal load profile should be considerably more favourable than for air conditioning. However, this does not consider the possibility of rather sharp longdistance travel peaks on holidays.

We extended our U.S. investigation to Canada. Quebec, like Norway, is a hydro dominant electric generation location that is winter peaking [9], as is British Columbia [10]. Northern hydro-based electric generating systems that are winter peaking have extra capacity for summer charging of long-distance travel needs of general purpose BEVs. From a carbon emissions reduction perspective these are excellent locations to promote PEVs. Encouragement of the general purpose BEV would be in the interest of increasing the summer seasonal use of the existing grid, probably without any need for generating capacity additions.

Only three provinces subsidized PEVs. These were British Columbia, Ontario, and Quebec. Among Canadian cities, Vancouver in British Columbia had a moderate Pacific Coast climate, like the U.S. states with a Pacific Coastline (Fig. 3). Otherwise, Canadian cities were generally colder than those in the Northern U.S. Quebec is significantly colder than the coldest city in Norway, Oslo. Ontario is comparable in climate to Norway, though probably colder on average. Major Ontario cities are on Lake Ontario and are warmer than Oslo. In seasonal temperature terms, Toronto Canada is very similar to Trondheim Norway.

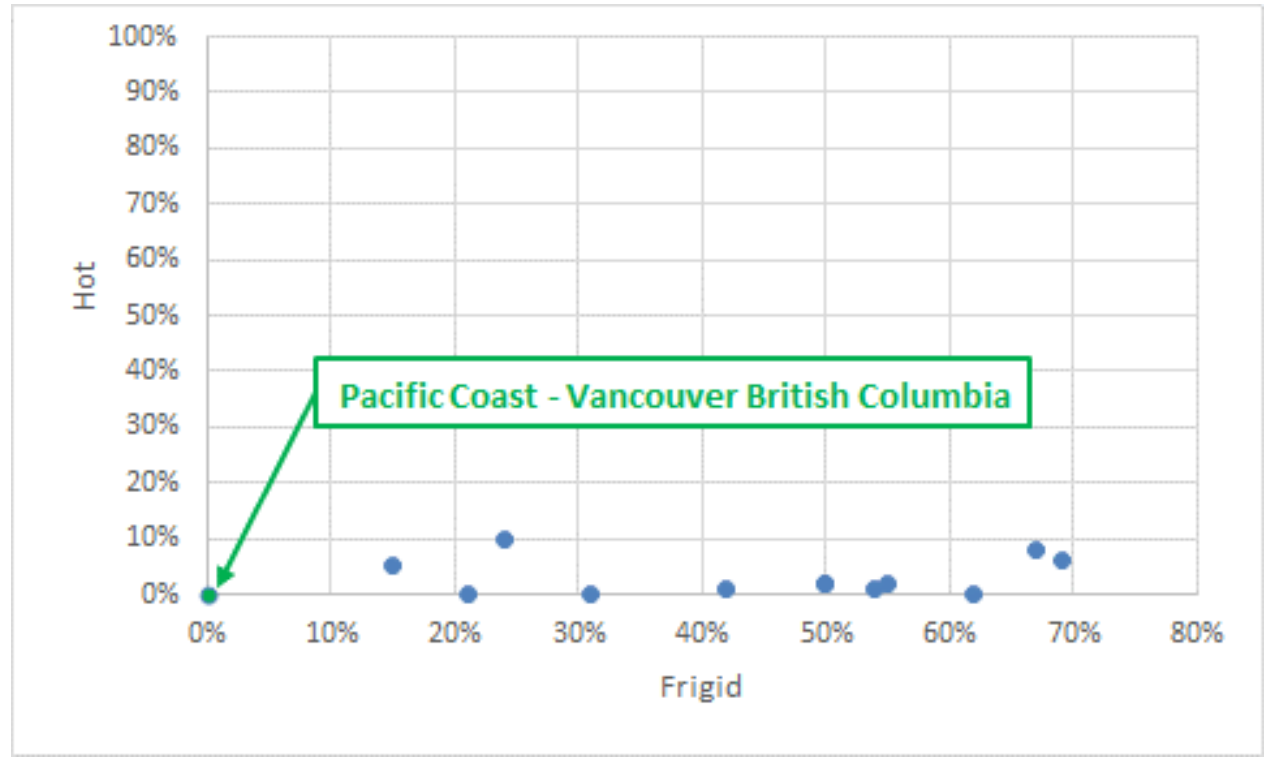

Fig. 3 Peak extreme temperature shares of Canadian cities (Weatherspark.com, averages).

\subsection{Weather influences, but does not dominate BEV vs. PHEV choice}

While the overall 2014 BEV share for Canada, at $54 \%$ was higher than in the U.S., at $47 \%$, the pattern of BEV shares among the three provinces with subsidies did show the expected patterns related to temperature. Cold Quebec had 45\% BEVs, Ontario had 58\%, and moderate temperature British Columbia had 73\%. Without Norway, the 2014 European BEV share was 49\%. The climate trends in North America implied a higher BEV share in Europe. A candidate explanation for the low BEV share in Europe is the presence of a very popular PHEV model not yet available in the United States - the Mitsubishi Outlander PHEV.

The Outlander PHEV would fit in our mid-market segment (Table 2). It is considerably less expensive than the Porsche S-E Hybrids, has a larger battery pack and more range. Looking at its U.K. rating relative to the Porsche's, we estimate it could be rated at about $35 \mathrm{~km}$ range under U.S. tests. Multiple U.S. states have selected incentives that are lowest for PHEVs, while some have given no incentives. The Outlander, with a $12 \mathrm{kWh}$ battery pack, would qualify for a U.S. federal incentive of $\$ 5833$. Its range would be less than the cut-off point for highest PEV subsidy in several U.S. states. Since its introduction in Europe in 
2013, the Outlander PHEV SUV has about doubled the sales of the more expensive leading general purpose BEV, the Tesla [11]. A point made in [3] was that once California and Georgia (\$5000 BEV-only subsidy) were removed from the U.S. data set, Ford PHEVs and General Motors extended range electric vehicles (EREVs) far outsold BEVs in the mass market consumer segment (Table 1).

\section{Background/Classification}

Two major classes of PEV are examined: (A) plug-in hybrids (PHEVs) - PEVs that allowed an engine to provide power assist during battery charge depletion; (B) Battery electric vehicles (BEVs) that never allow an engine to provide power assist. Within the PHEV class there are three important sub-classes. The "blended" mode PHEV allows the engine to assist the battery at times during charge depletion, and operates as a hybrid once the battery pack is depleted. These powertrains are complex. The Ford Energi system and Prius Plug-in Hybrid system are of this type. The extended range electric vehicle (EREV), such as the Chevrolet Volt and Opel Ampera, also uses a complex hybrid powertrain that is operated on gasoline once the battery has been depleted. However, it never allows the engine to assist electric drive while the battery is being depleted. The range extended electric vehicle (REX), such as the BMW i3 REX, uses a relatively simple "series" hybrid powertrain to allow the vehicle to run on gasoline once the battery pack has been depleted. Certain types of REX, as defined in California Air Resources Board (CARB) regulations, can earn regulatory credits as if they are BEVs. These are called BEVx vehicles.

In 2011 [12] CARB proposed that this new subclass of BEV be created, called the BEVx. This BEV would be allowed to have an "auxiliary power unit" (APU) that would allow driving on gasoline (or other future low greenhouse gas (GHG) fuels for a range equal to or less than the range of electric operations. These vehicles must have an electric range of 80 miles in a rather undemanding driving test. The APU could not be operated until the battery pack was completely empty. Thus a tested total range of 160 miles would be the maximum allowable. Limited top speed on gasoline was requested by CARB. Such vehicles were said to allow "improved regional driving capability" but "not use for long-distance driving". Half of a manufacturers' full ZEV credits could be met with such vehicles. In 2012 this [12] was made a part of California regulations applicable to 2017. BMW, the leader in advocating this technology, produced it (i3) and is selling it, with both a BEV (i3) and BEVx (i3 REX) version. The REX federal window sticker estimated range under more aggressive testing than for CARB certification, is 72 miles. Total range is 150 miles

Table 1 Attributes of U.S. Mass Market PEVs studied

\begin{tabular}{|c|c|c|c|c|c|c|c|c|c|c|}
\hline Make / Model & $\stackrel{\infty}{\stackrel{2}{\hbar}}$ & 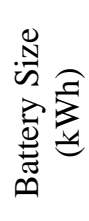 & 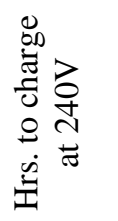 & 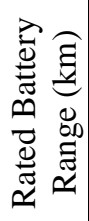 & 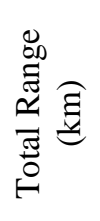 & 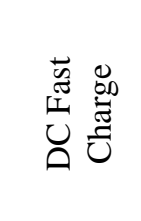 & 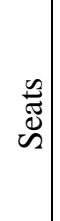 & 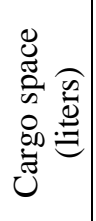 & 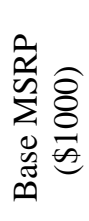 & 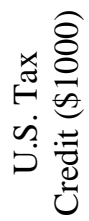 \\
\hline Toyota Prius & PHEV & 4.4 & 1.5 & 18 & 870 & No & 5 & 623 & 30.0 & 2.5 \\
\hline Honda Accord & PHEV & 6.7 & 0.7 & 21 & 920 & No & 5 & 255 & 39.8 & 3.6 \\
\hline Ford C-MAX & PHEV & 7.6 & 2.5 & 31 & 885 & No & 5 & 544 & 32.6 & 4.1 \\
\hline Ford Fusion & PHEV & 7.6 & 2.5 & 31 & 885 & No & 5 & 232 & 33.9 & 4.1 \\
\hline Chevrolet Volt & EREV & 16.5 & 4 & 61 & 611 & No & 4 & 510 & 34.2 & 7.5 \\
\hline Mitsubishi iMiEV & BEV & 16 & 7 & 100 & 100 & $\begin{array}{l}\text { CHAde- } \\
\text { MO std. }\end{array}$ & 4 & 368 & 23.0 & 7.5 \\
\hline Smart EV & BEV & 17.6 & 6 & 109 & 109 & No & 2 & 340 & 25.0 & 7.5 \\
\hline Ford Focus EV & BEV & 23 & 3.6 & 122 & 122 & No & 5 & 400 & 29.2 & 7.5 \\
\hline VW e-Golf & BEV & 24 & 4 & 134 & 134 & $\begin{array}{l}\text { SAE } \\
\text { Std }\end{array}$ & 5 & 480 & 33.5 & 7.5 \\
\hline Nissan Leaf & BEV & 24 & $\begin{array}{c}8 @ \\
3.6 \mathrm{~kW} \\
\end{array}$ & 135 & 135 & $\begin{array}{l}\text { CHAde- } \\
\text { MO opt. }\end{array}$ & 5 & 680 & 29.0 & 7.5 \\
\hline
\end{tabular}


Table 2 Attributes of U.S. Mid-market PEVs studied

\begin{tabular}{|c|c|c|c|c|c|c|c|c|c|c|}
\hline Make / Model & $\sum_{\ominus}^{\infty}$ & 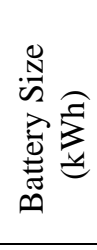 & 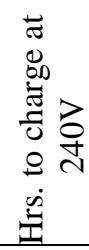 & 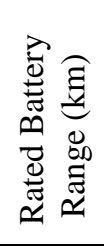 & 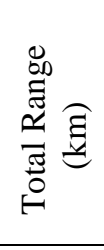 & 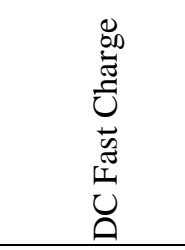 & $\begin{array}{l}\stackrel{\tilde{J}}{\tilde{D}} \\
\tilde{\omega}\end{array}$ & 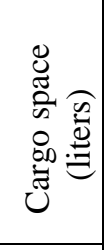 & 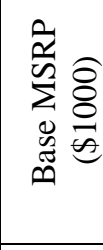 & 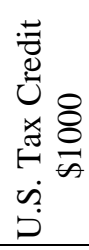 \\
\hline BMW i3 REX & REX & 22 & 4 & 116 & 241 & SAE option & 4 & 425 & 45.2 & 7.5 \\
\hline BMW i3 & $\mathrm{BEV}$ & 22 & 4 & 130 & 130 & SAE option & 4 & 425 & 41.4 & 7.5 \\
\hline $\begin{array}{c}\text { Mercedes- } \\
\text { Benz B-Class } \\
\end{array}$ & BEV & $\begin{array}{l}28 \\
31\end{array}$ & 3.5 & $\begin{array}{l}140 ; \\
167\end{array}$ & $\begin{array}{l}140 ; \\
167\end{array}$ & No & 5 & 620 & 41.5 & 7.5 \\
\hline Toyota RAV4 & BEV & $\begin{array}{c}35 \\
41.8 \\
\end{array}$ & 6.0 & 166 & 166 & No & 5 & 1030 & 49.5 & 7.5 \\
\hline
\end{tabular}

Table 3: Attributes of U.S. Luxury/performance PEVs studied

\begin{tabular}{|c|c|c|c|c|c|c|c|c|c|c|}
\hline Make / Model & 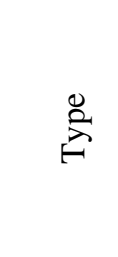 & 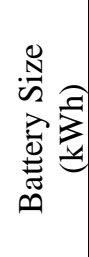 & 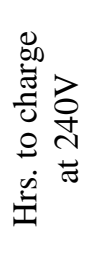 & 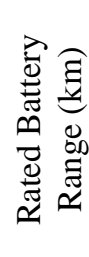 & 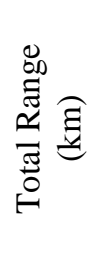 & 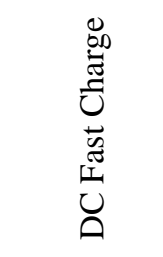 & $\begin{array}{l}\tilde{n} \\
\tilde{\Xi} \\
\omega\end{array}$ & 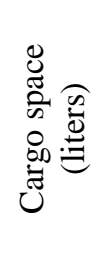 & 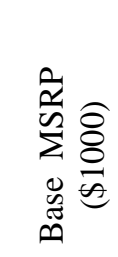 & 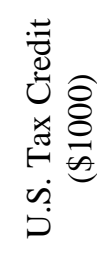 \\
\hline Mclaren P1 & PHEV & 4.7 & 3 & 31 & 483 & No & 2 & $\mathrm{n} / \mathrm{a}$ & 1150.0 & none \\
\hline BMW i8 & PHEV & 5.2 & 2 & 24 & 531 & No & 2 & 140 & 135.7 & 3.8 \\
\hline Porsche 918 & PHEV & 7.8 & 3 & 19 & 676 & No & 2 & $\mathrm{n} / \mathrm{a}$ & 845.0 & 3.7 \\
\hline $\begin{array}{c}\text { Porsche } \\
\text { Panamera }\end{array}$ & PHEV & 9.4 & 3 & 26 & 869 & No & 5 & 450 & 99.0 & 4.8 \\
\hline $\begin{array}{l}\text { Porsche } \\
\text { Cayenne }\end{array}$ & PHEV & 11 & 3 & 23 & 772 & No & 5 & $\mathrm{n} / \mathrm{a}$ & 76.4 & 5.3 \\
\hline Cadillac ELR & EREV & $\begin{array}{c}16 . \\
5 \\
\end{array}$ & 5 & 60 & 547 & No & 2 & 310 & 75.0 & 7.5 \\
\hline Tesla Model S† & BEV & $\begin{array}{l}60- \\
90\end{array}$ & $\begin{array}{l}10- \\
12\end{array}$ & $\begin{array}{l}335 \\
434\end{array}$ & $\begin{array}{l}335 \\
434\end{array}$ & $\begin{array}{c}\text { Tesla } \\
\text { Super opt. }\end{array}$ & $\begin{array}{l}5 \\
- \\
7\end{array}$ & 740 & $\begin{array}{l}69.9 \\
85.0\end{array}$ & 7.5 \\
\hline
\end{tabular}

$\dagger$ Seven different powertrains were available in 2015 models, most available in late 2014

\section{Methods}

Records of new plug-in electric vehicle (PEV) sales or registrations for model years 2014-2015 for the U.S., Canada and Europe are examined.

Two kinds of battery electric vehicles (BEVs) - those using only electrical power without an internal combustion engine (BEV) or BEVs that use internal combustion engines to support range extending hybrid operation, but only after battery charge depletion (General Motors Volt/ELR/Ampera and the BMW i3 range extender) (BEVx). For the BEVs, there were seven competing technological options to provide refuelling beyond the charge depletion distance: (1) SAE level 1 charging (2) SAE level 2 charging (3) gasoline supported HEV operation (4) battery swapping (5) Tesla's superchargers (6) Japanese developed CHAdeMO fast charging (7) SAE Combo fast charging. DC Fast chargers (items 5-7) and Level 2 charger (item 3) totals are compiled. Tables 1-3 shows the type of DC fast charger used by make and model. Note that, in all but one case, the DC fast charger is an option. The BEV with the shortest range, the Mitsubishi MiEV came with a standard CHAdeMO DC fast charger. Note that none of the U.S. PHEVs in 2014 was equipped with a DC Fast charger. The European Mitsubishi Outlander PHEV, however, does come 
equipped with a DC fast charger. All PEVs being discussed are capable of SAE level 1 and 2 charging. It is generally recognized that SAE level 1 charging is primarily for overnight charging at residences. However, it is also an option for workplace charging, where vehicles are parked a long time. Options 3-7 support long-distance travel.

Taking the need of member states to make focused infrastructure investment choices among these seven options, case study is used to determine causes of success and failure in the presence of significant financial PEV purchase incentives that were greatest for the BEV, or exclusive to it. Cases of unusual success in terms of PEV vehicle share were the states of California, Georgia, Oregon and Washington in the U.S. and Norway and Estonia in Europe.

To gauge the completion between long distance driving fuel option 3 (i.e. PHEV, EREV and REX) vs. charging options 2 and 5-7 (BEV), we compiled Level 2 charger counts and cumulative numbers of DC fast chargers (5-7) to gain an overview perspective. Influence of presence or absence of financial incentives for PEV purchase is examined.

Within a number of different groupings we examine the share of PEV class A (gasoline long distance assist) vs. class B (only electrical operation).

In closing, we consider selected trends in class A vs. B sales from 2014-2015.

\section{Results}

\subsection{PEV success, charging infrastructure and financial incentives}

Our first comparison is a cross-section for 2014 (Table 4). We collected and adjusted data from a number of sources, compiling values as comparable as we could [11, 13-21].

Table 4. 2014 PEV success, charger intensity and financial incentives by state, province and nation.

\begin{tabular}{|c|c|c|c|c|c|c|c|}
\hline Geographical unit & $\begin{array}{c}2014 \text { PEVs } \\
\text { sold per } \\
1000 \\
\text { persons }\end{array}$ & BEV $\%$ & $\begin{array}{c}\text { DC Fast } \\
\text { chargers } \\
\text { per million }\end{array}$ & $\begin{array}{l}\text { L2 per } \\
\text { million }\end{array}$ & $\$ / B E V$ & $\$ /$ PHEV & $\begin{array}{c}\text { EVSE } \\
\text { support }^{\mathrm{a}}\end{array}$ \\
\hline Estonia & 0.27 & $93 \%$ & 11 & 124 & $\begin{array}{l}22,000 \\
(2012)\end{array}$ & 0 & yes \\
\hline Denmark & 0.29 & $94 \%$ & 26 & 143 & 15650 & 0 & yes \\
\hline Netherlands & 0.90 & $19 \%$ & 10 & 700 & \multicolumn{2}{|c|}{5365} & a little \\
\hline Norway & 3.81 & $92 \%$ & 154 & 998 & 16910 & 0 & yes \\
\hline California & 1.47 & $45 \%$ & 18 & 164 & 10000 & 9000 & yes \\
\hline Georgia & 0.87 & $92 \%$ & 13 & 68 & 12500 & 0 & a little \\
\hline Michigan & 0.37 & $8 \%$ & 1 & 58 & 7500 & 5750 & yes \\
\hline Oregon & 0.45 & $60 \%$ & 52 & 199 & 7500 & 5750 & yes \\
\hline Vermont & 0.37 & $24 \%$ & 56 & 190 & 7850 & 6100 & 0 \\
\hline Washington & 0.53 & $68 \%$ & 18 & 167 & 9460 & 6600 & yes \\
\hline Other U.S. & 0.13 & $41 \%$ & - & - & 7500 & 5750 & often 0 \\
\hline Quebec & 0.26 & $45 \%$ & $4.6(2016)$ & $125(2016)$ & 7450 & 7450 & 931 (home) \\
\hline British Columbia & 0.18 & $73 \%$ & $9.7(2016)$ & 155 (2016) & $0^{*}$ & $0^{*}$ & $0^{*}$ \\
\hline Ontario & 0.12 & $58 \%$ & $3.8(2016)$ & $45(2016)$ & 7916 & 7916 & 931 (home) \\
\hline Other Canada & 0.03 & $50 \%$ & $<2$ & $15-195$ & 0 & 0 & 0 \\
\hline \multicolumn{7}{|c|}{$\mathrm{a}=$ yes mostly means some kind of business tax exemption, sometimes subsidy (see AFDC) } & \\
\hline \# prior incentives & ed in 2014 & & & & & & \\
\hline
\end{tabular}

In all cases highly successful PEV market penetration was achieved in member states that had significantly stronger total incentives for the BEV than for the BEVx, EREV, or PHEV. BEV exclusive incentives had the intended effect, driving BEV shares above 90\% (Estonia, Denmark, Norway, Georgia). However, 
significant financial incentives for BEVs without sufficient supporting investment in charging infrastructure significantly diminished the 2014 BEV sales per capita (Estonia and Denmark vs. Norway; Georgia vs. Norway). Between the Netherlands and Michigan, both ignoring DC fast charging, the level of investment in Level 2 charging appears to have been important. However, the Netherlands also subsidized PEVs. Looked at another way, when very little DC fast charging was provided, consumers did not purchase BEVs (Netherlands, Michigan).

Vermont and Oregon had about the same vehicle incentives and charging infrastructure availability per capita. Colder Vermont had a much smaller share of BEVs.

In cold Canada, most provinces chose not to subsidize PEVs. In the absence of any subsidy of 2014 PEVs, sales shares were very small ("Other Canada" vs. all other cases). When Quebec and Ontario subsidies were similar to the U.S., and infrastructure availability was greater (compare to Michigan), PEV sales per capita were lower than in the U.S. location. Generally, Canadian PEV sales per capita were lower in provinces that provided vehicle incentives and infrastructure than in warmer U.S. locations with a similar mix of PEV support.

Norway's success is even more impressive when the drawbacks of cold temperature are taken into consideration. Norway's results show that very strong across the board incentives, including intensive support of public charging infrastructure with both Level 2 and DC fast capability, can lead to market success for BEVs. On the other hand, this also illustrates that accomplishment of that goal was quite expensive.

The expense of sustaining BEV and PEV sales has caused some of the states that did so to take steps to cut subsidy costs. Three U.S. states that provided significant added (to federal incentives) support to PEV implementation in 2014 have reduced their support. California and Washington have restructured vehicle incentives to avoid subsidizing the PEVs in Tables 2 and 3. Georgia, among U.S. states the closest to Norway, has completely eliminated its BEV incentive, leading to sharp declined in sales of the Nissan Leaf. In Europe, Estonia ceased subsidizing BEVs. BEV sales stopped growing, but remained relatively steady [11]. The Netherlands modified its incentive program, leading to a temporary sharp drop in Mitsubishi Outlander sales.

\subsection{Competition between PEV type A (PHEV, EREV, REX) and type B (BEV)}

BMW i3. For U.S. policy purposes, our interest is whether or not the regulatory and financial systems might be impeding the development and implementation of a PEV type that might receive significant consumer acceptance. Our investigation is directed at the degree of desire for convenient long-range capability by consumers interested in PEVs generally. As Table 4 indicates, those states or nations that have strongly promoted BEVs and PEVs have done so successfully. If we include them in our investigation of consumer preferences for the nation, a biased result will be obtained. At the present time in the U.S., the only relatively "clean" test of the degree of preference for a range extension option is the BMW i3 and the i3 REX. To satisfy CARB regulators, the i3 REX is intentionally hobbled with respect to gasoline range (Table 2) and performance.

We removed the California and Georgia i3 sales results from our records of 2014 registrations. We found that $34 \%$ of i3 sales were for the BEV. Under CARB rules, only $52 \%$ of i3 REX sales would qualify for ZEV credits (34/66), even though it might be possible that the average REX would electrify more miles because of greater average use. We used the European Alternative Fuels Observatory [11] website and removed Norway from the overall PEV sales totals, then computed i3 BEV share. In 2014 the share was 48\%; in 2015 42\%. For Canada [22], we were only able to get "total Canadian EV fleet" numbers. The national share was $41 \%$. The weather effect showed up in the provincial totals. Cold Quebec had 35\%, Ontario 39\%, and mild British Columbia 46\%.

Volkwagen e-Golf and Golf GTE. Volkswagen, like BMW, now has both a type A (PHEV) and B powertrain in the same model, the Golf. The BEV, the e-Golf was introduced first. The PHEV Golf GTE followed soon after. The e-Golf is the only one of the two models available in the U.S. Neither model was available in Canada. In Europe the BEV share was 54\% in 2014, dropping to $12 \%$ in 2015, as Golf GTE sales jumped dramatically.

Mitsubishi Outlander PHEV. Although the arrival of the Outlander PHEV in North America has been announced in the past, the date has slipped. If it were available, it would fit into the mid-market group, based on list prices reported in the United Kingdom. In our companion paper [4], we estimated the mid- 
market share of BEVs in states without PEV incentives, obtaining an estimate of 37\%. In states with relatively neutral BEV vs. PHEV incentives, we obtained a share of $43 \%$. If we look at the same midmarket class in Europe there is a very large difference in the membership of the set. The Outlander PHEV SUV, which has all-wheel drive, is inexpensive enough to fit into the mid-market price range. Though they do not yet directly compete, it is considerably less expensive than Tesla's general purpose luxury/performance Model X SUV BEV with all-wheel drive. At the present time, if the Outlander is placed into the mid-market category, less than $15 \%$ of that portion of the European market would be BEVs.

While it is early in the period of evolution of PEVs, recent trends in Europe support the argument in [2] that the PHEV is the best alternative for the larger vehicle in multi-vehicle households. Consistent with [2], the greatest success of BEVs in Europe [11] is in smaller vehicles with limited range.

Aggregate evolution. While the luxury/performance sector represents a small portion of the market and therefore a small proportion of total gasoline consumption, it is of interest as a launching pad for advanced technology. $23 \%$ of long-distance trips for visiting friends and relatives are by air, and $16 \%$ of vacation trips are by air [8]. For customers who do not intend to use a vehicle for such long-distance travel, range needs may be more limited. Possibly this market is not yet saturated. In the luxury/performance market in North America, the general purpose BEV continues to do well.

In contrast to the market expanding European shift to the mass and mid-market PHEV SUV, North America was limited by PHEV availability problems in 2015. North America continued to see expanding success of the long-range luxury/performance Tesla "general purpose" BEV models. Tesla sales increased in 2015 compared to 2014 in both the U.S. and Canada. Unfortunately, while the Tesla increased sales and captured more share, mass market PEVs in North America suffered. Two PHEV models were "in transition". The Plug-in Prius was not available, as the old model was discontinued. Supplies of the Chevrolet Volt were limited during a model change-over. With PHEV supply limited, overall North American PEV sales were stagnant, while BEV share rose as Tesla success offset sharp Nissan Leaf declines [3].

In 2014 without Norway included, the BEV share in Europe was 49\%. In 2015, after very successful sales years for new Volkswagen Group PHEVs (Golf GTE and Audi A3 e-Tron), BEV share dropped to 34\%. The phenomenon was not confined to Europe as a whole. Norway altered incentive rules to allow some PHEV s to obtain support. In Norway the BEV share also dropped - from $92 \%$ to $78 \%$.

\subsection{Conclusions}

Greatest PEV market success to date has been accomplished with a balanced combination of vehicle incentives and infrastructure investment.

Convenient long-distance travel capability in larger family sized PEVs is essential for market success. Achieving PEV success in such vehicles is important to realize significant fleet-wide gasoline and greenhouse gas reduction. If long-range general purpose BEVs are the chosen path these must be supported by extensive investment in DC fast charging facilities. For the United States, if such a path were exclusively followed, it could cause needs for additional generating and grid capacity to provide electricity for summer travel, when the U.S. system peaks. Canada and Northern Europe do not have this problem since their utilities are winter peaking.

Determination of the most cost effective means of achieving mass market success in electrifying national fleet kilometres has been investigated. Results suggest that inclusion of a full function hybrid mode option in the PEV portfolio of a manufacturer can greatly increase overall mass market success of the manufacturers' electric drive powertrain investment.

Cost effective expansion of the PEV market into colder climate regions may require adaptation of thinking by regulators, with a more balanced strategy to both (A) achieve overall fuel saving and greenhouse gas reduction and (B) provide clean air in urban areas.

\section{References}

1. Hirsch, J. California emissions rules charge debate over all-electric cars vs. hybrids. Los Angeles Times. Nov. 19, 2015. (http://www.latimes.com/business/autos/laautoshow/la-fi-hy-plugin-hybrids20151120-story.html). 
2. Tamor, M. and M. Milacic. Electric vehicles in multi-vehicle households. Transportation Research Part C. 56 (2015) 52-60.

3. Santini, D.J. et al, Plug-in Vehicle Attributes' Influence on U.S. Sales in 2014 in States without Preferential Incentives for ZEVs. EVS29 Symposium, Montréal, Québec, Canada, June 19-22, 2016

4. Zhou, Y. et al (2016). An Assessment of Causes of PEV Success Across U.S. Metro Areas. EVS29 Symposium, Montréal, Québec, Canada, June 19-22, 2016

5. Vergis, S. and B. Chen (2015). Comparison of plug-in electric vehicle adoption in the United States: A state by state approach. Research in Transportation Economics 52 (2015) 56-64.

6. AleaSoft Energy Forecasting. Assessment of Electricity Consumption in Western Europe for the first half of 2013. July 9.

7. Nordic Energy Regulators, Nordic Market Report 2014. Report 4/2014.

8. Sivaraman, V., A.R. Pinjari and S.E. Polzin (2016). Long-Distance Travel for Visiting Friends and Relatives (VFR) and Leisure Purposes: Empirical Analysis and Modeling Framework. Paper TRB 16-6751, presented at the Annual Transportation Research Board Meeting, Washington DC 2014 (Jan.)

9. Hydro Quebec Website. Spreading out your Electricity Consumption when it's Very Cold. Accessed March 24, 2016 (HTTP://WWW.HYDROQUEBEC.COM/RESIDENTIAL/ENERGYWISE/UNDERSTANDING-AND-TAKING-ACTION/WINTER-CONSUMPTION/)

10. BC Hydro: Power Smart. Forecasting Growth: December 2012 long-term electricity load forecast. Accessed March 24, 2016 (https://www.bchydro.com/energy-inbc/meeting_demand_growth/forecasting_growth.html)

11. European Alternative Fuels Observatory, http://www.eafo.eu/vehicle-statistics/m1, accessed April, 2016.

12. California Air Resources Board. 2012 Proposed Amendments to the California Zero Emission Vehicle Program Regulations. Dec. 7, 2011.

13. Thiel, C. et al (2015). Electric vehicles in the EU from 2010 to 2014. European Commission Joint Research Centre Institute for Energy and Transport (https://ec.europa.eu/jrc/en/publication/eurscientific-and-technical-research-reports/electric-vehicles-eu-2010-2014-full-scalecommercialisation-near).

14. ChargeHub.com. Canada's Public EV Charging Stations Status - part 1 of 3. (https://chargehub.com/blog/en/canadas-public-ev-charging-stations-status/). March 242016.

15. Christian Science Monitor, http://www.csmonitor.com/Environment/Energy-Voices/2013/0904/TeslaMotors-goes-to-Europe, September, 2013.

16. Alternative Fuels Data Center, http://www.afdc.energy.gov/laws/state, accessed March, 2016.

17. Drive Oregon, http://driveoregon.org/discover/incentives/, accessed March, 2016.

18. Nobil, http://info.nobil.no/index.php/english, accessed March, 2016.

19. Zacks, http://www.zacks.com/stock/news/107674/tesla-opens-model-s-plant-in-europe, August, 2013.

20. Lyndhurst, B. Uptake, of Ultra Low Emission Vehicles in the UK, A Rapid Assessment for the Department for Transport, Office for Low Emission Vehicles, 2015.

21. Jin, L., S. Searle and N. Lutsey (2014). Evaluation of State-Level U.S. Electric Vehicle Incentives. White Paper. International Council on Clean Transportation, Washington DC. (Oct.). http://www.theicct.org/sites/default/files/publications/ICCT_state-EV-incentives_20141030.pdf

22. Stevens, M., Electric Vehicle Sales in Canada: 2015 Final Numbers. Feb. 9, 2016. http://www.fleetcarma.com/ev-sales-canada-2015/

\section{Acknowledgments}

The authors would like to gratefully acknowledge the sponsorship of the Vehicle Technologies Office of the U.S. Department of Energy.

The submitted manuscript has been created by Argonne National Laboratory, a U.S. Department of Energy laboratory managed by UChicago Argonne, LLC, under Contract No. DE-AC02-06CH11357. The U.S. Government retains for itself, and others acting on its behalf, a paid-up, nonexclusive, irrevocable worldwide license in said article to reproduce, prepare derivative works, distribute copies to the public, and perform publicly and display publicly, by or on behalf of the Government 


\section{Authors}

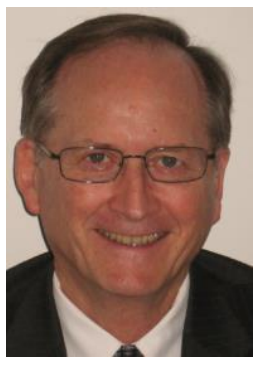

Danilo J. Santini, a senior economist at Argonne National Laboratory, obtained his Ph.D in Urban Systems Engineering and Policy Analysis from Northwestern University in 1976. From 1992-2008 Dr. Santini was a section leader within Argonne's Center for Transportation Research. He has served on the Alternative Fuels Committee of the National Research Council's Transportation Research Board since 1989, was chair from 1996-2002; is now Emeritus. From 2001-2014 he was one of the Department of Energy's technical representatives for the U.S. to the International Energy Agency Implementing Agreement on Electric and Hybrid Vehicles. In 2010 he was awarded the Society of Automotive Engineers' Barry McNutt prize for Excellence in Automotive Policy Analysis on Plug-in Hybrid Electric Vehicles.

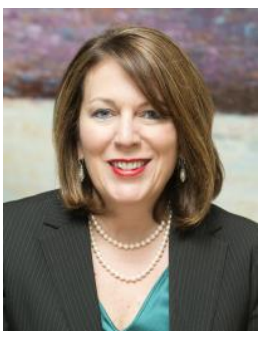

Marcy Rood is a principal environmental transportation analyst at Argonne National Laboratory (ANL). She provides support to the U.S. Department of Energy's (DOE) Clean Cities program and related international activities. Rood leads a team of ANL technical experts in the areas of electric drive, natural gas, and propane vehicles, renewable natural gas, idle-reduction technologies, and emissions and greenhouse gas modeling. She provides research, analysis, training, and communication products to the Clean Cities network. As well, she oversees a collegiate internship program that provides student assistance to Clean Cities coalitions. Recently, she spearheaded the five-year strategic planning process for the National Clean Cities program. Since 1995, Rood helped implement the mission of the DOE Clean Cities program.

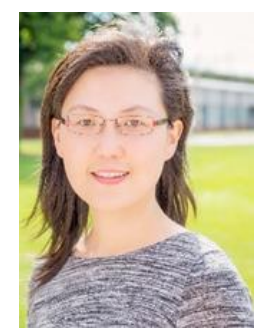

Yan Zhou is a transportation systems analyst at Argonne National Laboratory. At Argonne, she has been developing Long-Term Energy and GHG Emission Macroeconomic Accounting Tools which are widely used by government agencies, research institutes and consulting companies to project energy demand and analyse greenhouse gas emissions of different transportation sectors and evaluate the impact of adoption of renewable fuel and advanced vehicle technologies in these sectors. In addition, she has been collecting international sales data of advanced vehicle technologies and providing market trend and niche analysis for the Department of Energy's Vehicle Technology Office. She received her masters and Ph.D. degree in Transportation Engineering from Clemson University, South Carolina.

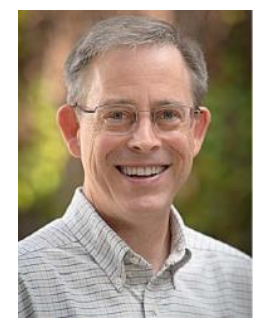

Thomas Stephens is a Transportation Systems Analyst at Argonne National Laboratory, where his work focuses on assessing energy use and emissions from advanced-technology vehicles as well as their potential costs and market potential. He has a Ph.D. in Chemical Engineering from the University of Massachusetts. In 2015 he received the DOE Vehicle Technologies Distinguished Achievement Award for economic, market, and integrated vehicle technology analysis.

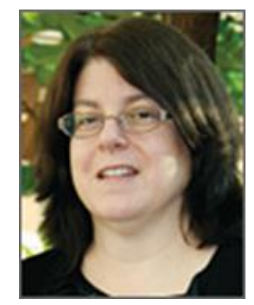

Linda Bluestein has been co-director of Clean Cities since 2008. She has been instrumental in promoting opportunities with regard to electric vehicle community readiness and promoting the work accomplished across the country in this area. Previously, Ms. Bluestein was the regulatory manager for Energy Policy Act (EPAct) fleet requirements at DOE's VTO, where she worked on compliance, enforcement, and writing regulations for the State and Alternative Fuel Provider fleet regulatory program.

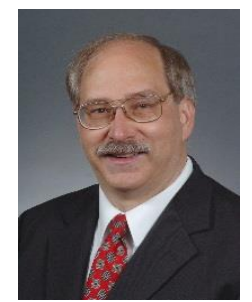

James Miller is Deputy Director of the Energy Systems Division at Argonne National Laboratory. $\mathrm{He}$ is also the Secretary-General of the International Energy Agency's Implementing Agreement on Hybrid and Electric Vehicles. He received a Ph.D. in Physics from the University of Illinois, and MBA from the University of Chicago. 